\title{
"Jesús" en la carta a los Hebreos
}

\author{
Josep Oriol Tứí V.S.J. \\ Facultad de Teología de Cataluna, Barcelona, \\ Centro de Reflexión Teológica, San Salvador.
}

En un trabajo muy reciente publicado en estas mismas páginas se hacía referencia, como de paso, a la importancia del tema del Jesús terreno en la carta a los Hebreos. ${ }^{1}$ Las breves reflexiones que siguen quisieran ampliar un tema que tiene la peculiaridad de haber sido percibido por la exégesis mucho antes de que la cuestión del Jesús histórico se planteara en toda su complejidad. En efecto, ya el comentario de B.F. Westcott (1909) hace referencia a la importancia de este aspecto de la enseñanza de Hebreos, ${ }^{2}$ y J. Moffat, en su comentario de 1924, subraya que las referencias al Jesús histórico son en este documento tan frecuentes y detalladas, que es imposible dejarlas al margen. ${ }^{3}$ Por otra parte el interés y estudio de este tema se percibe no solamente en la atención que le dedican los comentarios (para citar alguno reciente: los de G.W. Buchaman ${ }^{4}$ y $\mathbf{H}$ Braun ${ }^{5}$ ), sino también y especialmente en trabajos publicados en los últimos treinta años (O. Cullmann, M. Rissi, U. Luck, E. Grasser y J. Roloff). ${ }^{6}$

Sin embargo, a pesar del interés que muestran estos trabajos ${ }^{7} y$ de las inequívocas afirmaciones sobre la importancia del tema, ${ }^{8}$ uno no puede zafarse a la impresión de que no hemos alcanzado una valoración suficientemente madura de este aspecto de la enseñanza de la carta a los Hebreos. Las razones para ello son múltiples. Eri primer lugar hay que hacer referencia a la complejidad del escrito y a la dificultad, a pesar de intentos muy meritorios, ${ }^{9}$ de definir el tipo de comunidad que ha acuñado una presentación a la vez tan nueva y tan audaz. Pero, además, está el problema del tipo de trasfondo cultural que deja entrever el escrito. Parece que Hebreos ( $y$ aquí no estaríamos tan lejos de la comunidad joánica) sea un punto de encuentro en el que se han dado cita movimientos culturales tan diversos como el filonismo alejandrino ${ }^{10}$ y el rabinismo palestino, ${ }^{11}$ pasando por la gnosis helenística ${ }^{12}$ y el misticismo judío de la Merkabah. ${ }^{13}$ Finalmente, para no quedarnos en niveles tan generales, hay que notar que es, en concreto, la cristología de Hebreos la que continúa siendo de una magnitud muy compleja, como puede constatarse patentemente en el último comentario de $\mathrm{H}$. Braun. ${ }^{14}$

Si tomamos mínimamente en serio estos problermas y dificultades, nuestro trabajo tendrá el límite inevitable de la provisionalidad. Esto hay que tenerlo presente todo el tiempo, para no dar a nuestras reflexiones una solidez y firmeza 
que no pueden pretender. Sin embargo, el tema que abordamos es un tema planteado por el texto mismo de Hebreos: como es bien sabido la llamada carta a los Hebreos habla de Jesús explícita y sorprendentemente utilizando el nombre "Jesús" tout court. ${ }^{15}$ Por consiguiente, la pregunta por el sentido de esta forma de referirse a quien ha penetrado los cielos y se halla coronado de gloria y honor, no sólo es una pregunta legítima, sino que es una pregunta necesaria si queremos abordar la cristologla de este escrito.

Por consiguiente, partimos de una hipótesis que convendrá ir comprobando a cada paso: si esta forma de referirse al sumo sacerdote de nuestra salvación no será una peculiar manera de subrayar la humanidad de este pionero de la fe. En una palabra si no estamos ante una forma bien peculiar de hacer referencia al Jesús terreno. $Y$ si es así, en qué sentido, con qué características y con qué consecuencias. Caso de que nuestra hipótesis se vaya confirmando, es posible que podamos sacar consecuencias acerca de la llamada cuestión del Jesús histórico en el Nuevo Testamento. Al fin y al cabo Hebreos es un documento muy diverso de los evangelios sinópticos y si bien tiene puntos de contacto con el evangelio de Juan, ${ }^{16}$ sin embargo, el marco narrativo ha desaparecido por completo. 17 De aquí que nuestro trabajo pueda ser también una modesta contribución a ampliar el tema del Jesús histórico más allá de las estrechas fronteras de los relatos evangélicos. En este sentido se halla en plena continuidad con el trabajo sobre el evangelio de Juan que hemos citado al comienzo. ${ }^{18}$

\section{1. "Jesús" en la carta a los Hebreos}

A. Vanhoye dice que Heb. 2,9 da por primera vez el "nombre de hombre" a aquél que el escrito ha llamado hasta este momento "hijo," "primogénito," "Dios" y "Señor."19 Se trata de un nombre de hombre porque lo hace patente Hebreos a través de la aplicación del mismo nombre a aquel que nosotros acostumbramos a traducir como "Josué." 20 En este sentido el nombre de Jesús es más que el nombre "Cristo," ya que se trata de un nombre bíblico, que tiene connotaciones de testimonio bíblico.21

Ahora bien, una cosa es dar un nombre de hombre a un personaje determinado y otra cosa es que este nombre tenga connotaciones de humanidad. Esto es lo que debemos de comprobar a través del uso del mismo en Hebreos. Como es bien sabido el nombre de "Jesús" se encuentra en este sentido en diez textos de Hebreos que debemos citar con un cierto detalle:22

- "... el que ha sido abajado un poco respecto de los ángeles, Jesús, se encuentra, a causa de la muerte que ha sufrido, coronado de gloria y honor" (2,9).

- "Por tanto, hermanos santos, que comparten una vocación celestial, piensen en el apóstol y gran sacerdote de nuestra confesión, Jesús.." $(3,1)$.

- "Teniendo, pues, un gran sacerdote eminente que ha atravesado los cie-

los, Jesús, el hijo de Dios, mantengamos firme la confesión (de fe)" $(4,14)$

- "... la esperanza propuesta. Ella es para nosotros como una áncora del al-

ma bien firmemente fijada, que penetra más allá del velo a donde ha entrado por nosotros como precursor Jesús, llegado a ser gran sacerdote para siempre como lo fue Melquisedeq" $(6,18-20)$. 
- "... según esto (Sal. 104.4), Jesús se ha convertido en garante de una alianza mejor" $(7,22)$.

- "De esta forma, hermanos, tenemos plena confianza de acceder al santuario de los santos por (en) la sangre de Jesús" $(10,19)$.

- "... teniendo los ojos fijos en aquél que es el iniciador y consumador de nuestra fe, Jesús. El cual, renunciando al gozo que se le proponía soportó la cruz sin miedo a la ignominia y está sentado a la diestra del trono de Dios" $^{\prime \prime}(12.2-3)$.

- "(y se han acercado)... al mediador de una nueva alianza, Jesús, y a la sangre purificadora que habla mejor que la de Abel" $(12,24)$.

- "... esta es la razón por la que Jesús, a fin de santificar al pueblo con su propia sangre, padeció fuera de la puerta (de la ciudad)" $(13,12)$.

- "Que el Dios de la paz que ha resucitado de entre los muertos en (por) la sangre de una alianza eterna al gran pastor de las ovejas, nuestro Señor Jesús, les purifique..." $(13,20)$.

No es posible hacer un análisis detallado de todos estos textos. ${ }^{23}$ Vamos a limitarnos a hacer cuatro observaciones sobre los mismos, procurando sacar algunas consecuencias de cara a nuestro tema.

La persona de Jesús es alguien conocido, y Hebreos no considera necesario referirse a él añadiendo explicaciones o ilustraciones. Algunos de los textos citados son especialmente claros en este sentido: 2,$9 ; 7,22 ; 10,19$ y 13,12. Hay una clara familiaridad de la comunidad de Hebreos con Jesús. La identidad de Jesús es un dato bien conocido para Hebreos.

Todos los textos citados, sin excepción, hacen referencia o bien a la muerte de Jesús $(2,9 ; 7,22$, cf. 7,$23 ; 13 ; 20)$, o bien a su sufrimiento $(2,9 ; 3,1$, cf 2,18 ; $4,14$, cf. 4,$15 ; 13,12)$, o bien a su sangre $(10,19 ; 12,24 ; 13,12 ; 13,20)$. Uno de los textos $(12,2)$ habla explicitamente de la cruz. ${ }^{24}$

La identidad de Jesús es ulteriormente calificada en estos textos mediante la aposición de títulos o nombres: gran sacerdote $(3,1 ; 4,14 ; 6,20)$; iniciador y consumador de la fe $(12,2)$; precursor $(6,20)$; mediador $(12,24)$ y Señor $(13,20)$. Conviene recordar aquí que Hebreos tiene tres textos sobre Jesús con la expresión lèsoús Christós:

— "Es en esta voluntad (la de Cristo ct. 10,5) que hemos sido santificados por la oblación del cuerpo de Jesucristo ephapax" $(10,10)$.

- "Jesucristo es el mismo ayer y hoy, y lo será siempre" $(13,8)$.

- "... que él (Dios) realice en nosotros lo que es agradable a sus ojos, por mediación de Jesucristo a quien sea la gloria por los siglos de los siglos. Amén" (13,21).

Parece, por consiguiente, que con el nombre de Jesús entramos en una visión grandiosa, en una presentación cristológica de gran envergadura. $Y$ no deja de ser sorprendente que junto a los grandes títulos (Kyrios; Christós; ho huios; to huios tou theou) encontremos el nombre de Jesús, presentado sin pretensiones, con gran sencillez. Pero, al mismo tiempo, usado de una forma que resulta prácticamente intercambiable con los grandes títulos. ${ }^{25}$

De esta brevísima reflexión sobre los textos del nombre de Jesús podríamos concluir que nuestra hipótesis inicial no resulta en absoluto discordante. Más bien podrlamos reformular nuestro punto de partida preguntando ino estaremos ante 
una cristología que, junto a los trazos de la gloria y el triunfo, expresados con los grades títulos cristológicos, quiere subrayar también la huma nnidad de Jesús y lo hace precisamente a través del uso del nombre de hombre del este salvador que ha alcanzado un lugar permanente junto a Dios? De hecho, como hemos indicado, parece que estamos ante una serie de textos que subrayan precisamente el sufrimiento, la sangre y la muerte. Es por tanto posible que Hebreos quiera recalcar con el uso del nombre "Jesús" la vertiente humana y terrena de este mediador de la salvación. ${ }^{26} \mathrm{Al}$ mismo tiempo que asegura, contra cualquier tipo de gnosis, el carácter terrenal de la acción salvifica que nos conduce al culto celestial. Esto es lo que hemos de analizar.

\section{2. "Jesús" en la cristologla de Hebreos}

La cristología de Hebreos se describe desde hace tiempo como cristologla en tres estadios: pre-existencia-abajamiento-exaltación y se hace referencia a los modelos de Filipenses 2,5-11, o también 1 Timoteo 3,16, o a la misma cristología joánica como representantes de esta concepción cristológica. ${ }^{27} \mathrm{~A}$. Vanhoye califica la cristología inicial de Hebreos 1-2 como cristología tradicional en un sentido sensiblemente idéntico.28

Difícilmente se puede negar que Hebreos ofrece, en su presentación cristológica, el esquema en tres estadios. Sin embargo, hay que añadir inmediatamente que este esquema no ha sido asumido sin más. La primera impresión que produce una lectura de Hebreos es que el autor se ha dedicado fundamentalmente a trabajar y profundizar el tercer estadio. En efecto, el tema nuevo del sacerdocio de Jesús ocupa la parte central del escrito y constituye la base de todas las exhortaciones que se hacen a los lectores. Es en Jesús glorificado donde se ha realizado plenamente todo lo que el antiguo ritual habla previsto. Desde un punto de vista teológico la audaz novedad de Hebreos se centra en este punto capital. ${ }^{29} \mathrm{Y}$ cristológicamente se concreta en el titulo de gran sacerdote. 30 Porque de hecho otros titulos prácticamente nuevos apuntan a la misma realidad: tanto el título de pródromos, 31 como el de mesitês 32 como el de apostolos 33 vienen a ilustrar la función sacerdotal de Jesús respecto de los hombres.

Es aqui donde hay que situar toda la argumentación central de Hebreos que por resultar de sobra conocida no vamos a reproducir aquil en detalle. Nos contentaremos con recordar aquellos aspectos relevantes para nuestro tema.

El punto de partida de todo el argumento de Hebreos es lo que A. Vanhoye ha calificado como la situación actual de Cristo, ${ }^{34}$ es decir, Cristo glorificado. En los momentos claves de la argumentación Hebreos presenta a Cristo glorificado como punto de referencia fundamental: $1,5-14 ; 3,1-6 ; 7,1-28$. Con ello se hace patente también el interés pastoral del escrito: no se argumenta al margen de la situación actual de la comunidad, sino que más bien se habla de la experiencia de salvación que la comunidad ha experimentado. Se habla del Jesús que actúa ahora como mediador. 35

Pero el argumento no se detiene aqul. Al fin y al cabo la situación actual de Cristo es el objeto de la homologla, de la confesión comunitaria. ${ }^{36}$ El autor va más allá y elabora una fundamentación escriturística de la realidad actual de Cristo 
gran sacerdote para justificar a la comunidad la posibilidad del acceso a Dios. Es bien conocido el papel y uso del Salmo 110,1-4 en el hilo de esta argumentación. El estudio estructural de la carta lleva a constatar la utilización de este salmo en momentos claves de Hebreos, 1,$13 ; 8,1 ; 10,12$ y 12,2 por una parte, y 5,6;5,10; 6,20 y todo el capítulo 7, por otra. 37

Ahora bien, como momento interno de esta argumentación y fundamentación de la realidad sacerdotal actual de Jesús, el autor hace referencia a un tercer paso: la fundamentación del sacerdocio de Jesús se da de la mano con la interpretación de su muerte en términos de sacrificio ofrecido por él mismo. ${ }^{38} \mathrm{De}$ aquí las referencias al sufrimiento, a la muerte y a la sangre de Jesús. ${ }^{39}$ Sin embargo, y esto hay que subrayarlo, se habla de esta muerte y de esta sangre como de realidades que afectan a Jesús en la actualidad, a pesar de que, desde un punto de vista histórico, se hayan dado en el pasado. ${ }^{40}$ Jesús está ante Dios con su sangre. Por ello puede interceder eficazmente. ${ }^{41}$

Por consiguiente, parece que el autor ha ampliado notablemente el esquema de tres etapas al que antes nos hemos referido. $Y$, en consonancia con el talante exhortativo de muchos fragmentos de Hebreos, ha iluminado la situación actual de la comunidad. Este es el lugar de preguntarnos por el sentido del recurso a Jesús. Porque según Hebreos el glorificado, 42 el que está sentado a la derecha $_{1}{ }^{43}$ el que intercede, ${ }^{44}$ el que ha abierto camino 45 es precisamente "Jesús." ¿Quién es, por tanto, este "Jesús"? ¿Qué es lo que Hebreos quiere subrayar con estas forma de referirse al gran sacerdote?

Lo primero que debemos preguntarnos aquí es ¿cuál es el contenido de la acción mediadora de Jesús? $O$, si se quiere, ¿qué trazos dan a conocer la función salvífica de este Jesús sentado a la derecha de Dios? La respuesta a esta pregunta es fundamental porque sólo a través de esta respuesta podremos constatar si Hebreos ha ampliado efectivamente la tercera etapa de la cristología. O si ha hecho otra cosa.

Si examinamos un poco más de cerca el argumento de Hebreos veremos inmediatamente que, si bien es verdad que el autor habla siempre de Jesús en la medida que este Jesús es accesible ahora a la comunidad, (y por consiguiente habla siempre de Jesús glorificado y sentado a la derecha de Dios), también es cierto que toda la argumentación se centra en la manera como este Jesús ha alcanzado este status. La argumentación cristológica quiere justificar ante todo la situación actual de Jesús.

Esto se hace patente en el primer capitulo y en las referencias al Jesús entronizado, intercesor, "el que ha entrado," ect.46 Pero en cambio la parte central de la carta $(8,1-10,18)$ se dedica precisamente a desarrollar la forma concreta como Jesús ha llegado a ser gran sacerdote. Y lo hace recogiendo los textos de la primera parte donde ha anunciado el hecho programáticamente: 2,918 y 5,7-10. Por consiguiente, to que.Hebreros está haciendo no es ampliar directamente la tercera etapa de la cristologia tradicional, sino más bien profundizar la segunda. Es decir, para hablar del sacerdocio actual de Jesús (este es el objetivo de Hebreos), de hecho, nos da una amplia descripción de la manera concreta como este Jesús ha llegado a ser gran sacerdote.

Por ser este un aspecto muy conocido del mensaje de Hebreos, no parece necesario detenernos más en él. Para ilustrar su influjo en el tema que queremos 
desarrollar bastará hacer referencia a un concepto bien central de la carta: el de la teleiôsis de Jesús, es decir, el que se refiere a la realización plena $\circ$ al perfeccionamiento de Jesús. Este concepto y los relacionados con él ( télos, teleioun, teleiotês, teleios) tienen una presencia notable en Hebreros 47 y juegan un papel importante en su argumentación. Por lo que se refiere a Jesús, el verbo teleioun sirve para expresar la necesidad de una realización a través del sufrimiento (lo cual viene anunciado programáticamente en 2,10: "era conveniente... llevar a la plena realización al iniciador de la salvación;" se realizó en la pasión y muerte de Jesús: 5,7-9; y condujo a Jesús a una situación nueva: 7,28$)$. Jesús ha sido "perfeccionado." $Y$ lo ha sido a través del sufrimiento vivido en fidelidad hacia Dios (5,7-9).

Por consiguiente, existe un momento fundamental donde se da este perfeccionamiento. Jesús, en los días de su vida mortal, no era todavía sacerdote (hay que recordar que Jesús por nacimiento no pertenece a ninguna tribu sacerdotal: 7,13; por otra parte tenemos en 8,4 una afirmación muy audaz en este sentido: "si estuviera en la tierra no sería sacerdote, habiendo quienes ofrezcan dones según la ley;" finalmente el sacerdocio de Jesús es muy superior al sacerdocio terrenal, tal como atirma 8,6: "en realidad es un sacerdocio muy superior el que le es otorgado ya que es mediador de una alianza mucho mejor, basada en promesas mucho más grandes"). Pero Jesús alcanzará la dignidad sacerdotal a través de la acción de Dios $(5,6.10 ; 7,28) .48$ Y esta dignidad se da después de la muerte interpretada como sacrificio ("él, en cambio, después de haber ofrecido un sacrificio único por los pecados, está siempre sentado a la diestra de Dios" 10,12$)$, precisamente en su entronización $(4,14 ; 8,1)$. Hijo ya lo era, sacerdote, en cambio, lo ha de llegar a ser. ${ }^{49}$ Por lo tanto, Jesús ha llegado a ser sacerdote a través de su muerte. Esta formulación, por audaz que pueda parecer, tiene un firme punto de apoyo en el texto. ${ }^{50}$

De todo esto se puede deducir que el autor de Hebreos al intentar clarificar para los lectores la función actual de Jesús, se ha visto obligado a fundamentar la realidad de la confesión ${ }^{51}$ a base de analizar más de cerca el fundamento de la segunda etapa de la cristología tradicional. Por ello, el contenido y la aportación de Hebreos es precisamente la ampliación y profundización de esta segunda etapa de la cristología como medio de explicar mejor la tercera.

Todo esto se confirma con un agudo estudio de A. Vanhoye sobre la Aktionsart de los aoristos con que el autor de Hebreos subraya el hecho sacrificial de Jesús. ${ }^{52}$ Nota Vanhoye que mientras en la descripción del oficio sacerdotal Hebreros emplea siempre el presente o bien el infinitivo, cuando habla del hecho sacrificial de Jesús utiliza siempre el aoristo. Y ello en un doble sentido: en cuanto que utiliza el verbo prospherein (o también anapherein) en aoristo, pero también acompaña estos textos con aoristos de otros verbos (emathen, epathen, ekathisen, eisêlthen, ypemeinen $)^{53}$ que subrayan el carácter puntual del hecho descrito. Notemos además que, a fin de no dejar ninguna duda sobre la unicidad del hecho descrito, singulariza la acción añadiendo a estas frases el hapax o el ephapax (en un caso el mia thysia). ${ }^{54}$ De aquí se deduce que, mientras la situación actual de Jesús en su acción sacerdotal es descrita con verbos en perfecto $(7,25.28 ; 12,2)$ y se enfatiza de esta manera el carácter de duración del hecho, cuando el autor se refiere al sacrificio de Jesús, a su oblación, a su 
entrada en el cielo, utiliza siempre el aoristo. Se está subrayando con ello que Jesús ha accedido al trono de Dios mediante su sacrificio único; pero en cambio no parece que podamos decir con propiedad que este sacrificio perdure en el cielo. 55

Todo esto tiene por lo menos dos consecuencias para nuestro tema: lo que subraya Hebreos es el carácter único y esencial del sacrificio de Jesús, el hecho de que no se repite nunca más; ${ }^{56}$ pero además, que, de hecho, Jesús es sacerdote porque lo ha llegado a ser a través de su vida y, más en concreto, de su muerte. En un cierto sentido parece que la existencia terrenal de Jesús, sin haber sido directamente calificada como sacerdotal, es, sin embargo, plenamente sacerdotal. $57 \mathrm{O}$, por lo menos, al referirse a la vida y a la muerte de Jesús para justificar la realidad de su tarea sacerdotal ahora, el autor ha de buscar su punto de apoyo fundamental en los hechos capitales de la vida y la muerte de Jesús. La vida terrena de Jesús resulta así esencial para el argumento de Hebreos, porque su muerte ciertamente lo es.

Ello nos lleva a una última cuestión, que recoge nuestras consideraciones iniciales sobre la cristologla de Hebreos: ¿cómo se relacionan las tres etapas de la cristología de la carta? Comencemos por la segunda y la tercera etapas: ¿se relacionan entre sí como un antes (vida terrena) y un después (vida glorificada)? Para los lectores de Hebreos, el autor ha dejado bien en claro que el pasado es ciertamente pasado.58 Pero, de hecho, los trazos que caracterizan al Jesús exaltado no han borrado las marcas de la cruz, la carne y la sangre. Es a través del Jesús terreno, del Jesús que ha derramado su propia sangre, del Jesús que ha padecido y ha sido tentado que los lectores pueden identificar la figura del gran sacerdote digno de confianza y capaz de compadecerse de ellos. Sin los trazos de la vida mortal de Jesús, estaríamos ante una figura importante, pero lejana y mítica $y$, en el fondo, inaccesible. Si bien es verdad que el Jesús glorificado no continúa ofreciendo un sacrificio que ha llegado a su plenitud con la muerte (una muerte que se da una sola vez), ${ }^{59}$ sin embargo, Jesús está delante de Dios con su carne, con su sangre y con su ignominia. En este sentido, la relación entre las dos últimas etapas de la cristología de Hebreos tiene una óptica bien cercana a la que tenemos en el evangelio de Juan: en éste para hablar del Jesús exaltado y, por tanto, presente, se ha de apelar a los rasgos fundamentales de su vida terrena. 60 Lo mismo parece ocurrir en la carta a los Hebreos. En ambos escritos hay una sobreposición de estas dos últimas etapas. Tenemos en estos escritos una gran concentración cristológica en la figura de quien es al mismo tiempo el exaltado y el terreno, "el hijo" y aquel a quien se llama Jesús. ${ }^{61}$

Podemos preguntarrnos finalmente qué ha ocurrido con la primera etapa de la cristologla de Hebreos. Como ocurre en el evangelio de Juan, la primera etapa sólo puede ser objeto de confesión. La confesión se da de la mano con la tradición (Heb. 1-2). Pero, en el fondo, esta confesión lleva al autor a constituir esta primera etapa en el verdadero hilo conductor de todo el proceso cristológico. En el fondo se trata de la defensa más convincente contra cualquier tipo de peligro adopcionista. Jesús es siempre "el hijo." Lo es tanto antes de su homoiôsis solidaria (1,4-11), como lo continúa siendo en su abajamiento ("siendo como era, hijo, aprendió a través de lo que sufrió" 5,7$)$ y no deja de serlo en su entronización como sacerdote, causa de salvación para todos $(7,28)$. Jesús es siempre el mis- 
mo, como se dice explícitamente $(13,8$ cf. 1,12 y 7,24). Pero ni su status como hijo, ni su superioridad respecto a los ángeles y a Moisés ${ }^{62}$ le habrían permitido un acercamiento misericordioso a los hombres. Su solidaridad fue necesaria. $Y$ continúa siéndolo.

A la luz de estas breves consideraciones la cristología de Hebreos aparece como una magnitud muy acabada. La práctica intercambiabilidad de los títulos cristológicos que antes hemos notado ya parecía apuntar a ello. ${ }^{63}$ El autor de Hebreos no se ha sentido desbordado ante las dificultades que presentaba la novedad introducida en el esquema tradicional a través de la afirmación de la realidad sacerdotal de Jesús. Ni se ha encogido cuando ha tenido que valorar en profundidad el momento clave para predicar de Jesús el título de gran sacerdote: su vida entregada $(9,14$, cf. $5,7-9)$. Ahora bien, precisamente esta reflexión sobre la realidad de la vida y la muerte de Jesús apunta a la posibilidad de leer la carta a los Hebreos con los "ojos fijos en Jesús," tal como el escrito recomienda a sus lectores $(12,2) .{ }^{64}$ Es posible que una relectura de Hebreos con esta actitud contemplativa nos confirme en nuestra hipótesis inicial acerca del sentido de la terrenalidad que el autor quiere conferir a la forma concreta como se refiere al salvador: es Jesús.

\section{Jesús y la misericordia}

La novedad de Hebreos es la aplicación a Jesús del título de gran sacerdote. Esto resulta tan conocido que parece que no debería ser necesario explicitarlo. Pero si lo hemos de recordar es precisamente porque aquí está, en profundidad, la razón última de la importancia de la consideración de la realidad terrena de Jesús en Hebreos. Normalmente se subraya la novedad del título y la imposibilidad de deducirlo de la tradición cristiana anterior o verosímilmente anterior. ${ }^{65}$ Es también conocido que el sacerdote, según Hebreos, ha de ser capaz de compadecerse, de comprender el sufrimiento. 66 No consta que este rasgo caracterice ninguna figura sacerdotal, pero aun en el caso que la caracterizara, ¿como sabe el autor de Hebreos que el Jesús exaltado es capaz de metriopathein ? Sólo puede saberlo a través de los datos que caracterizaron la vida de Jesús. ${ }^{67}$ De la misma manera que sólo puede hablar de la inmunidad de pecado a través del conocimiento de la vida del mismo Jesús. ${ }^{68}$ Por otro lado, la exhortación a contemplar a este Jesús exaltado marcado con los trazos del abajamiento (y esta es una verdadera característica de la parenesis de Hebreos) apunta a un talante de lectura fuertemente contemplativo, que saca de la relectura de la vida de Jesús los datos que confirman su capacidad de compadecerse y su función salvifica respecto de los hombres. Por ello nos conviene releer la carta con los ojos fijos en Jesús, iniciador de nuestra fe, es decir, creyente, ${ }^{69}$ obediente a la voluntad de Dios. ${ }^{70}$ Este va a ser el último aspecto de este trabajo.

\subsection{La vida de Jesús en Hebreos}

Ya hace tiempo que la exégesis de Hebreos ha ido recogiendo una serie de datos de la vida de Jesús que hoy interesa recordar. Son indicaciones muy concretas, que otros documentos neotestamentarios presentan como trazos o episodios de la vida de Jesús. ${ }^{71}$ 
- Jesús salió de la tribu de Judá $(7,14)$;

- inició la predicación de la salvación $(2,3)$;

- tuvo oyentes, que transmitieron su predicación $(2,3)$;

- fue fiel y obediente a Dios $(3,2 ; 10,5-9)$, y aprendió a obedecer a través del sufrimiento $(2,10 ; 5,8)$;

- tuvo opositores (12,3);

- fue tentado, sin caer en el pecado $(2,18 ; 4,15)$;

- oró, suplicando a Dios con lágrimas y grandes clamores (5,7-10);

- murió en la cruz (12,2), fuera de la puerta de la ciudad $(13,12)$;

- subió y fue elevado a la derecha de Dios $(8,1 ; 13,20 ; 10,12)$;

- existe la convicción de que volverá $(9,28$ cf. 10,25).

Estos textos y fragmentos de Hebreos son una muestra patente de que este documento no está directamente interesado en rehacer biográficamente la vida de Jesús. En definitiva, porque los datos cronológicos y topográficos faltan totalmente. Por otro lado muchos de estos datos tienen un tono genérico que no enlaza con la historiografía, ni siquiera con la de aquel tiempo. Si no tuviéramos otros documentos neotestamentarios, sería totalmente imposible situar estos datos "históricos" en un marco temporal, puesto que faltan los puntos de enlace con datos y situaciones conocidos por otro camino. ${ }^{72}$

Ahora bien, si el sentido fundamental no es el de la biografía de Jesús, entonces resulta que muchos de estos datos se han reproducido en Hebreos con una finalidad bien definida; servir de soporte al argumento sobre el sacerdocio de Jesús. Es decir que si pueden ser considerados datos soteriológicamente relevantes, ${ }^{73}$ lo son en la medida que constituyen un punto de referencia importante en la argumentación sobre la identidad del gran sacerdote que ahora intercede por los hombres ante Dios.

El argumento tiene dos vertientes: el sacerdote ha de tener acceso a Dios y a los hombres. El primer aspecto ya ha quedado suficientemente definido en la presentación de la situación de Cristo en el capítulo 1.74 Por consiguiente la realidad de Jesús, de la vida de Jesús es importante para el autor de Hebreos en la medida que su relación con los hombres resulta indispensable para justificar su status de gran sacerdote ahora. Por ello la referencia a Jesús, a su vida y a su muerte, no son subrayadas en virtud de una necesidad genérica, ni siquiera en virtud de una cierta concepción bíblica según la cual los sucesos históricos se constituyen en sucesos salvíficos (cosa que el autor no niega) ${ }^{75}$, sino más bien on la medida que hacen de Jesús uno de nosotros, capaz de compadecerse y de hacerse cargo de nuestra condición llena de debilidad y finitud (recordemos el temor a la muerte y la superación de este temor por parte de Jesús, en la medida que ha asumido esta muerte).

Es en este marco hermenéutico donde hay que situar la importancia de los datos sobre la realidad del Jesús terreno. Esta es la óptica que nos ha de permitir valorar los trazos que el autor ha subrayado. Es posible que se trate de un aspecto muy conocido. 76 Pero hay que tener presente que es en definitiva este aspecto el que nos ha de llevar a valorar el sentido y alcance de la figura del Jesús terreno para la vida y la fe esperanzada de la comunidad de Hebreos. En este sentido hay una categoría que resulta definitiva, la de la "solidaridad," representada de diversas maneras en Hebreos. Veámoslo. 


\subsection{La solidaridad de Jesús con los hombres}

Entre los diversos lugares donde se trata este aspecto de la enseñanza de Hebreos $(2,5-18 ; 4,14-5,10 ; 9,11-14.24-28 ; 10,5-10.12-24)$ hay uno que sobresale claramente: la presentación de la situación de Jesús respecto de los hombres en 2,5-18. En este fragmento se habla de Jesús como hombre (anthrôpos y también huios anthrôpou , ${ }^{7}$ como el que ha sufrido la muerte (dia tou pathema tou thanatou v. 9), el que ha gustado la muerte (un claro hebraismo, v. $9 b)$; se afirma que el que santifica y los santificados ex henos pantes, es decir, que tienen el mismo origen ( $v$. 11); se dice que Jesús compartió la carne y la sangre (la condición humana, v.14) y que tomó sobre sí la descendencia de Abraham y no a los ángeles (v. 16). Finalmente, la homoiôsis es llevada a sus últimas consecuencias: "convenía que se asemejase en todo a los hermanos" ( $v$. 17). Por ello es capaz de compadecer a los tentados, porque también él fue probado (v. 18).

Es indudable que algunas de estas afirmaciones pueden sorprender. Al fin y al cabo parece que el autor no ha marcado límites a la solidaridad. Esto se hace especialmente claro en el v. 14: "por tanto, así como los hijos (ta paidia) participan ${ }^{78}$ de la carne y la sangre, así también igualmente participó él de las mismas..." La expresión "los hijos" es ciertamente inusitada, pero inteligible a la luz de la cita del v. 13. El argumento se hace con todo más fuerte: "si los "hijos" (hasta qué punto se trata de una imagen de origen gnóstico no lo podemos discutir aquí) participan de la condición humana, Jesús también deberá participar de la misma." Esto se anuncia con gran énfasis: kai autós... así también él... Pero en este caso el paraplesiôs no puede querer significar solamente "de modo parecido," sino que ha de implicar la plena igualdad, como de hecho lo subraya el v. 17 al no poner límites al kata panta. ${ }^{79}$ Porque es sólo un poco más adelante que el lector aprenderá que Jesús ha sido tentado sin haber caído en el pecado $(4,15)$. Por tanto, Jesús no participa de la condición humana de una forma distinta a como participan de ella los demás hombres, ni siquiera con un cuerpo extraordinario (cr. 10,5). Finalmente dentro de esta misma línea, tenemos la expresión meteschen tôn autón del v. 14 sin ulterior calificación. Su sentido no es ambiguo: también él participó de la carne y la sangre de la misma forma que participan de ellas los hombres. La ambigüedad de esta expresión se podría deber a un posible influjo gnóstico que no podemos discutir aquí. 80

Con este breve análisis puede quedar claro que Jesús, en la presentación de Hebreos, participa plenamente de la condición humana. Esta importante enseñanza de Hebreos se ampliará y matizará en otros momentos de la carta, donde aprenderemos que Jesús es capaz de compartir todas nuestras debilidades porque ha sido tentado kata panta (en todo, sin límites), pero sin caer en el pecado. ${ }^{81}$ Es por esto que ha sido constituido gran sacerdote y podemos acceder a él con la seguridad de ser comprendidos y de conseguir misericordia. Aprenderemos también que Jesús ha pasado por el temor ante la muerte, pero que ha superado esta delibidad a través de su fiel sumisión y que, por tanto, ha aprendido la obediencia y es capaz de salvar a todos los que le obedecen, etc.

En resumen, las afirmaciones de Hebreos sobre la solidaridad de Jesús con la vida humana no tienen límite. Lo cual da entrada a una ulterior consideración: con esta forma de argumentar Hebreos no solamente da sentido a la antro- 
pología de la comunidad, sino que además está implicando que, excepto en el pecado, la situación de los presuntos lectores ha sido compartida por Jesús. Con esta consideración no pocos datos antropológicos de Hebreos se iluminan y adquieren un talante cristológico que no les hubiéramos atribuido. Por tanto, si es verdad que en el fondo del argumento de Hebreos tenemos una aplicación cristológica a la vida cristiana y que los títulos de prodromos, archêgos tês soterias, archêgos kai teleiôtês tês pisteos ya apuntan en esta dirección, sin embargo, es toda la antropología de Hebreos la que ha de ser considerada cristológicamente. Y no solamente la vida cristiana en su sentido de fe confiada.

No es este el lugar de analizar en detalle los datos antropológicos que pueden ser interpretados cristológicamente. Pero sí conviene subrayar que mientras algunos datos antropológicos de Hebreos ya han sido interpretados cristológicamente, en cambio hay otros muchos que son susceptibles de este tipo de interpretación y que Hebreos no lo ha explicitado. Nos limitaremos a dar algunos ejemplos de ambos tipos de datos.

Entre los datos interpretados cristológicamente, resulta interesante constatar que los conceptos antropológicos de sarx ("carne" 2,14; 5,7; 10,20), haima ("sangre" 2.14; 9,12.14; 10,19; 13,12), anthrôpos ("hombre" 2,6), sôma ("cuerpo" 10,5 ), thanatos (muerte 2,9), astheneia (debilidad 5,2), pathema (sufrimiento $2,9)$ se aplican en Hebreros a Jesús.

Pero, en línea con lo que hemos indicado, la solidaridad de Jesús con la condición humana no tiene límite. Por tanto, también la situación del creyente está marcada por la existencia de Jesús. De aquí que, si bien algunos conceptos como el de tentación $(2,18 ; 4,15)$, soportar $(12,2$ cf. 12,1), sufrir la ignominia $(13,13)$ han sido interpretados cristológicamente, en cambio hay otros, como por ejemplo el de estar prisionero $(10,34)$, el de compartir $(13,16)$, el de hacer el bien $(13,16)$, el de ofrecer hospitalidad $(13,1)$, el de amarse los unos a los otros $(13,1)$, etc., que pueden también interpretarse a la luz de la existencia terrena de Jesús. 82

De aquí surge una última reflexión: la vida creyente alcanza, a la luz de la función actual de Jesús-gran sacerdote un carácter sacerdotal que antes no tenía. En este sentido las frecuentes exhortaciones a "entrar," a "acercarse," a "salir," tienen un talante sacerdotal que confiere un tono nuevo e inusitado a toda la existencia cristiana. Pero además conviene recordar lo que se ha dicho muy a menudo: Hebreos, con estas exhortaciones, no pide al creyente que salga del mundo y que lleve una vida desarraigada de su condición mortal. 83 Más bién ocurre lo contrario: es al hacer el bien y al crear solidaridad mutua como se está haciendo una ofrenda. ${ }^{84}$ La vida de cada día se convierte en una acción sacerdotal. La profanidad ha quedado abolida. ${ }^{85} \mathrm{Y}$ de rebote resulta que Jesús es sacerdote ahora porque lo fue durante su vida mortal, precisamente en el ofrecimiento de esta vida mortal. ${ }^{86}$ La existencia terrena de Jesús queda así iluminada a través de su status actual de gran sacerdote y el contenido de su acción sacerdotal de ahora, la misericordia, sólo se ha hecho posible porque Jesús, en su vida mortal, fue misericordioso. 87 


\section{Conclusión}

Nuestro trabajo tenía un objetivo muy ceñido: calibrar el interés de Hebreos por la terrenalidad de Jesús. Sin embargo, las consecuencias de este interés comprobado van más allá de la carta a los Hebreos. Por ello vamos a añadir una segunda consecuencia respecto al interés del Nuevo Testamento por el Jesús terreno.

En lo que se refiera a nuestra pregunta inicial, creo que hemos aportado suficientes datos para afirmar que Hebreos presenta un marcado interés por la terrenalidad de Jesús. $Y$, por consiguiente, el sentido fundamental del uso del nombre sin más parece responder a este interés por incluir la terrenalidad de Jesús en la cristología. Pero, en contra de lo que pueda parecer, el interés de Hebreos por el Jesús terreno no ha sido motivado por una valoración genérica de la "historia." Hebreos no ha mostrado interés en valorar los hechos salvíficos como hechos "históricos" sin más. El esquema de la historia salutis que preside la presentación de Jesús en otras obras neotestamentarias no parece haber sido el marco teológico fundamental para el autor de Hebreos. ${ }^{88}$ Más bien podríamos decir que su valoración del tiempo y de la historia es muy flexible y que la cronología no es para este escrito una magnitud intocable. 89

A pesar de ello el interés por la realidad humana de Jesús resulta verdaderamente extraordinaria en este documento. Sólo a través de la solidaridad de Jesús con la vida humana se llega a comprender que su función actual llena de compasión y de misericordia hacia los hombres pueda ser creída. La profundización en la realidad actual del gran sacerdote ha sido posible a través de la contemplación del Jesús terreno y de la consideración de su vida mortal envuelta en la debilidad, la tentación y el sufrimiento y coronada por una muerte que se hace garantía para los hombres por ser una muerte plenamente aceptada y, por tanto, plenamente humana. Como es bien sabido estamos ante una profunda transformación de la categoria de "sacerdote." Esta transformación ha sido posible precisamente a través de la contemplación de la vida y la muerte de Jesús. Como dice acertadamente J. Sobrino, el autor de Hebreos lo formularía asi: "sacerdote, ése es Jesús."90 Que esta presentación se dé con una punta polémica contra una concepción antigua y superada o más bien para justificar la ausencia de sacerdotes en la comunidad, no acaba de ser demasiado importante para nuestro argumento. ${ }^{91}$ Aunque indudablemente, el día que podamos despejar esta incógnita, nuestra aportación tendrá un sentido más concreto y específico.

Nuestro trabajo es una clara muestra de que la cuestión del Jesús terreno sigue siendo una cuestión actual en el estudio del Nuevo Testamento. Sin embargo a la luz de lo indicado podríamos preguntarnos si la terminología que se utiliza ("el Jesús histórico") no debería dar paso a una formulación que tenga en cuenta no sólo los evangelios sinópticos, sino que abarque también el interés de otros documentos neotestamentarios en Jesús, en su humanidad, en su terrenalidad. Porque, como hemos visto, el interés de Hebreos por el Jesús terreno no es fruto de una presentación que utilice el esquema de la historia salutis. Es la consideración de la solidaridad de Jesús con los hombres lo que da al tema del "Jesús terreno" un enfoque nuevo y profundo del tema de la humanidad de Jesús. Porque, además, nos enseña una forma nueva y concreta de "recuperación" de la humanidad de Jesús. Es a través de la confesión ${ }^{92}$ y de la consideración de la 
relación entre la situación de la comunidad y el Jesús exaltado que surge una relectura concreta de la vida de Jesús. Y a la luz de nuestra anterior aportación sobre el evangelio de Juan, 93 uno se pregunta si no debería ser ésta nuestra tarea cristológica por excelencia: ¿quién es Jesús para nosotros? ¿Quién es Jesús para cada comunidad? En este caso tanto la historización de Jesús en la vida de la comunidad joánica como la relectura de la vida de Jesús que hace Hebreos resultan puntos de referencia sumamente sugerentes. Ambos documentos han apelado a la vida de Jesús para iluminar la propia vida, para encontrar sentido a las propias preguntas y dificultades.

Lo que resulta interesante tanto en Hebreos como en el evangelio de Juan es que ambos documentos parten de la confesión de la comunidad. $94 \mathrm{Y}$, por consiguiente, se parte de la vida cristiana más o menos cuestionada, pero que, en cualquier caso, va haciendo camino. ${ }^{95}$ El problema no es, por consiguiente, un problema académico o retórico. Estamos ante un doloroso proceso de profundización en las virtualidades de la fe y del papel de Jesús, el hijo, el salvador, el que está sentado a la derecha del Padre. Pero también "uno de nosotros," "el hombre llamado Jesús."

Esta parece ser la enseñanza más profunda del tema que hoy hemos tratado. La cuestión de "Jesús" en la carta a los Hebreos es un ejemplo más de la amplitud de intereses y matices que puede tener la cuestión del Jesús terreno siempre que la tratemos dentro del marco hermenéutico de cada autor y de cada obra del Nuevo Testamento. Y esta cuestión todavía puede dar mucha luz a nuestra fe y a nuestra esperanza. ${ }^{96}$

\section{NOTAS}

1. "La vida de Jesús en el Evangelio de Juan," Revista Labnoamericana de Teología 3 (1986) 3-45.

2. Epislle to the Hebrews, London 1909, p. 49, según cita de M. M. Bourke, "Epistola a los Hebreos," en la obra en colaboración, Comentario Bíblico San Jerónimo, Tomo IV, Madrid, Cristiandad, 1972, p. 330.

3. "The allusions to the hislorical Jesus are not numerous, but they are too detailed and direct to be explained away," Hebrews, Edinburg 1957, p. II.

4. To the Hebrews, The Anchor Bible 36, New York 1972: "The signilicance of Jesus," pp. 253-255.

5. An die Hebräer, HNT 14, Tübingen 1984: Die chronologische Aporie der Hb-Christologie," pp. 32-33.

6. Citamos estos trabajos por orden cronológico: M. Rissi, "Die Menschlichkeit Jesu nach Hebr 5,7-8," publicado on Theologische Zeitschrift 11 (1955) 28-45; O. Cullmann en su obra Christologie du Nouveau Testament, Neuchatel-Paris 1958, pp. 7494. habla de Jesús como gran sacerdote e interpreta este título cristológico como una clara referencia a la obra terrena de Jesús; U. Luck, "Himmlisches und irdisches Geschehen im Hebráerbriel," publicado on Novum Testamentum 6 (1963) 192-215; E. Grāsser, "Der historische Jesus im Hebrāerbrief, en Zeitschnift für neutestamentli che Wissenschatt 56 (1985) 63-91; J. Roloff, " Der mittleidendeHohepriester. Zur Frage nach der Bededeutung des irdischen Jesus für die Christologie des Hebräerbriefes," apararecido en el Festschrift H. Conzelmann, Jesus Christus im Historie und Theologie, Tübingen 1975, pp. 143-166. Estos son los trabajos que tratan especificamente nuestro tema, pero hay otros muchos que lo tienen presente. Véase la nota siguiente. 
7. Interés que puede percibirse explícitamente en los trabajos de A. Vanhoye que se irán citando a lo largo de estas páginas (sobre todo en Situation du Christ. Epitre aux Hébreux 1 et 2. Lectio Divina 58, Paris 1969, pp. 255-394); puede verse también el reciente comentario de C. Spicq. L'Epitre aux Hébreux, Sources Bibliques, Paris 1977; O. Michel, Der Brief an die Hebräer, Meyers Kommentar XIII, Göttingen 1966, y en otros trabajos que se irán citando en las notas.

8. Un indicativo de esta importancia podría ser el acento en la unicidad del acontecimiento salvífico fundamental subrayada a través de las frecuentes referencias al hapax $y$ al ephapax (hapax en $6.4 ; 9,7.26 .27 ; 10,2 ; 12,26.27$; ephapax en 7,$27 ; 9,12 ; 10,10)$. Cf. en este sentido O. Cullmann, Cristo y el tiempo, Barcelona 1968, segunda parte, " El carácter temporalmente único de las distintas épocas de la salvación: ephapax," pp. 105-112. Sin embargo, como veremos, al dar a este aspecto un valor automáticamente histórico se corre el peligro de pasar por alto la especificidad de la aportación de Hebreos. El esquema de historia salutis no resulta relevante para la presentación cristológica de este documento. Cf. más adelante, lo que decimos en las conclusiones.

9. Véase por ejemplo G. Mora, La carta a los Hebreos como escrito pastoral, C. San Paciano 20, Barcelona 1974.

10. Esta es una de las aportaciones de la magna contribución de C. Spicq, L'Epître aux Hébreux, Estudes Bibliques, 2 vols., Paris 1952-53.

11. Es bien conocido el trabajo de $\mathrm{H}$. Kosmala sobre la relación entre Qumran y Hebreos: Hebräer, Essener, Christen. Studien zur Vorgeschichte der Frühkirchlichen Verkündigung, Leiden 1959.

12. El influjo que ha ejercido la tesis de E. Käsemann en los estudios sobre Hebreos es bien patente, a pesar de que hoy en día no se subscribirlan la mayorla de sus puntos de vista: Das wandemde Gottesvolk. Eine Untersuchung Zum Hebräerbrief, FRLANT NF 37, Göttingen 1939. Véase lo que decimos infra en la nota 96.

13. H. M. Schenke, "Erwägungen zum Rätsel des Hebräerbriefes," publicado en el Festschrift H. Braun, Neves Testament und christliche Existenz, Tübingen 1973, 421437.

14. Aunque esta es una caracterlstica que se encuentra en casi todos los trabajos de $\mathrm{H}$. Braun, su minuciosidad analítica no le permite alcanzar puntos de vista más globales o sintéticos (notablemente en su conocido trabajo sobre Qumran). Para H. Braun la cristologla de Hebreos se encuentra encerrada en un callejón sin salida: op.c. (nota 5), pp. 32-33. Hay que notar que la cristologla de Hebreos ha sido objeto de no pocos estudios, algunos muy recientes: F. Büchsel, Die Christologie des Hebräerbriefes, BFChTh 27-2, Gütersloh 1922; E. Schl. Fiorenza, "El promotor y consumador de nuestra fen en la obra en colaboración (ed. J. Schreiner). Forma y propósito del Nuevo Testamento, Barcelona 1973, 306-327; E. Grässer, "Zur Christologie des Hebräerbrieles," Eine Auseinandersetzung mit Herbert Braun, publicado en el Festschritt für $H$. Braun, Neues Testament und christliche Existenz, Tübingen 1973, pp. 195-206; W.R.G. Loader, Sohn und Hohepriester. Eine traditionsgeschichtliche Untersuchung zur Christologie des Hebräerbriefes, WMANT 53, Nuekirchen 1981.

15. Esta manera de referirse a Jesús no sólo resulta característica de Hebreos, sino que confiere a este escrito un cierto aire "evangélico." Los textos se citan más adelante.

16. Cf. lo que decimos más adelante en este sentido, Ya C. Spicq notaba hace años más de 16 paralelos entre Hebreos y Juan: L'Epître aux Hébreux, vol. I, Paris, 1952. pp. 109-131.

17. En cambio en el evangelio de Juan el marco narrativo constituye un aspecto fundamental del mensaje de esta obra. Cf. lo que decimos en el trabajo citado en la nota 1 supra. 
18. Esto se amplía en una obra en prensa que ha de aparecer a comienzos de 1987: Jesús y el evangelio en la comunidad joánica. Una introducción a la lectura cristiana del evangelio de Juan. Salamanca 1987.

19. "Le nom lui-même atteste l'humanité de la personne qui le porte, car "Jésus" est un nom d'homme," Situation du Christ, p. 286. En una obra más reciente comenta el mismo Vanhoye: "Le Christ apparaît pleinement homme, le seul homme en qui la vocation humaine se soit accomplie parfaitement," Prêtres anciens, prétre nouveau selon le Nouveau Testament, Paris 1980, p. 101.

20. Heb. 4,8 ef. Dt. 31,7 y Jos. 22,4 .

21. "The reason for that emphasis (namlich des Namens 'Jesus') is that the name is always more than the name of Christ, it is a biblical name carrying overtones of Scriptural Testimony to Jesus as Christ, "F. C. Synge, Hebrews and the Scriptures, London 1959, p. 20, según cita de O. Michel, op. c., (supra en la nota 7), p. 171.

22. En todos estos textos seguimos muy de cerca la traducción de la TOB.

23. Por ello nuestro trabajo no puede aspirar más que a formular una hipótesis sólida. Sin embargo, los 10 textos citados nos ponen en contacto con los conceptos cristológicos más importantes de toda la carta. Véase lo que decimos más adelante sobre la intercambiabilidad de los títulos cristológicos en la nota 25.

24. Aparentemente hay una excepción: 6,18-20. Pero Hebreos enlaza este texto con 10,20 mediante el concepto de velo (katapetasma, cf. también 9,3), el cual, a su vez, es identificado con la sarx de Jesús. La relación de este concepto con la muerte de Jesús se hace patente en los textos sinópticos: Mc. 15,38 y par. Son los únicos 6 textos del Nuevo Testamento que utilizan el concepto de katapetasma.

25. Este es un punto que convendrla analizar mucho más despacio. Aqul sólo vamos a hacer dos constataciones, suficientemente indicativas para nuestro trabajo: Jesús es el hijo $(3,1,6)$, es hijo de Dios $(4,14)$, Señor $(13,20)$, Cristo $(3,6 \mathrm{cp} .3,1)$. Pero también vice-versa, es decir, todos estos títulos se aplican a Jesús. Más aún, cada uno se identifica con todos los demás, de forma que se encuentran indistintamente dentro del mismo fragamento (cf. 4,14-5,10). A primera vista no parece que Hebreos utilice estos títulos para designar diversas etapas de la cristologla. Más bien parece que estamos ante una cristología muy acabada, como si se tratara de una magnitud sin fisuras. Todo esto se trata más despacio en el apartado 2.

26. La hipótesis también se podría formular de otro modo: los titulos nuevos de Jesús, como son prodromos, apostolos kai archiereys, archégos kai teleiotés, mésités (engyos), se aplican directamente a Jesús, no a los otros títulos. Parece por tanto que es a través de su vida mortal que Jesús llega a ser todo lo que los tltulos indican. Pero, por encima de todo, Jesús llega a ser sacerdote. Los textos relevantes para todo esto son los siguientes: 2,9-10 (archégos tés sóterias); 6,20 (prodromos); 3,1 (apostolos kai archiereys); 12,24 (mésités cf. engyos en 7,22).

27. Este aspecto es subrayado especialmente por $\mathrm{J}$. Roloff en el articulo citado supra en la nota 6. Puede verse también lo que dice en este sentido $H$. Braun, An die Hebráer, p. 33.

28. Además del análisis que hace en Situation du Christ, puede verse ahora Prétres anciens, prétre nouveau, citado en la nota 19, pp. 91-98.

29. El argumento de Hebreos comporta una critica casi inusitada del culto antiguo, el cual viene a ser identificado con la idolatrla: "C'est lá une audace á peine croyable," A. Vanhoye, Prêtres anciens, prêtre nouveau, p. 202.

30. Hebreos afirma que tenemos un "sacerdote eminente" (iereys megas 10,21); que tenenmos un "gran sacerdote eminente" (archiereys megas 4,14) o simplemente un "gran sacerdote" (archiereys 4,$15 ; 8,1)$. $Y$ de hecho identifica a este gran sacerdote con Jesús: "teniendo un gran sacordote eminente... Jesús, el hijo de Dios" $(4,14)$; "el apóstol y gran sacerdote de nuestra profesión de fe, Jesús" $(3,1)$; "Cristo, llegado 
a ser gran sacerdote de los bienes futuros" $(9,11)$. Sobre el titulo de gran sacerdote puede verse ahora el resumen de $\mathrm{H}$. Braun, "Jesus, der himmlische Hohepriester," An die Hebräer, pp. 71-74 (con una selecta bibliografla).

31. Hopou prodromos hyper hémón eisélthen lésous... archiereys genomenos eis ton aiôna, 6,20. Conviene recordar que prodromos es un hapax en el Nuevo Testamento, pero que está en conexión con archêgos (Heb. 2,10; 12,2 cf. Act. 3,15 y 5,31).

32. Heb. 12,24 cf. 8,6 y 9,15 . Como hemos insinuado antes hay que relacionar este título con la función de garante (engyos), y esta función se apoya precisamente en la de archiereys que tiene Jesús: cf. 7,22-25 donde se explicita esta función sacerdotal de Jesús (7,24 cf. 7,11-12).

33. Apostolos kai archiereys... lésous, $3,1$.

34. Una justificación muy detallada de este aspecto de la estructura de Hebreos puede encontrarse en su trabajo La structure littéraire de l'épitre aux Hébreux. Studia Neotestamentica / Paris 1962. Para una exposición muy resumida puede verse también Le Message de l'Epitre aux Hébreux, Cahiers d'Evangile 19, Paris 1977.

35. Véase, por ejemplo, Heb. $6,4-6 ; 10,26 ; 12,22$. Como resulta de sobra conocido Hebreos intenta salir al paso de las dificultades de una comunidad que ha perdido la fuerza de su empuje inicial. Véase la obra de G. Mora, citada en la nota 9, pp. 234242.

36. Este es un tema central de Hebreos que deberla ser analizado más despacio. Que hay una homologia en la comunidad es evidente $(3,1 ; 4,14 ; 10,23 ; 13,15)$, pero, ¿cuál es su contenido? Cf. V. H. Neufeld, The earliest Christian Confessions, New Testament Tools and Studies 5, Leiden 1963, pp. 134-140. E. Grässer no ha entrado directamente en este aspecto (Der Glaube im Hebräerbrief, Marburg 1965) y, sin embargo, deberla analizarse más en detalle el carácter cristológico de la confesión que no resulta tan claro como quisiera G. Bornkamm, "Das Bekenntnis im Hebräerbrierf," Gesammelte Aufsătze II, Beitrăge zur Evangelische Theologie 28, München 1963, pp. 188-203.

37. A. Vanhoye, Situation du Christ, p. 103.

38. Heb. 9,11-14.25; 10,10;13,12.

39. Hebreos habla de la sangre de Jesús $(2,14 ; 9,12-14 ; 10,19 ; 13,12)$; de la muerte de Jesús $(2,9.14 ; 5,7 ; 9,15.27 ; 12,2)$ y de su sufrimiento $(2,9.10 .18 ; 5,8 ; 9,26-28$; 13,12).

40. Este punto lo explicitaremos más adelante, al hablar del "momento" en que se sitúa la acción sacrificial de Jesús.

41. U. Luck, op. c. (supra en la nota 6), pp. 206-213 y el interesante articulo de W. Thüsing, "Lasst uns hinzutreten (Hebr. 10,22)! Zur Frage nach dem Sinn der Kulttheologie im Hebräebrief," publicado en Biblische Zeitschrift, Neue Folge 9 (1965) 1-17, especialmente pp. 12-13 y 15.

42. Coronado de gloria $2,7.9$ (cf. 3,3 ).

43. Usando el SI, 110: Heb. 1,3.13;8,1;10,12; 12,2 .

44. Heb. 7,25.

45. Jesús es el prodromosy el archégos: 2,$10 ; 6,22 ; 12,2$.

46. En Hebreos Jesús es el que se encuentra ante Dios. El que ha atravesado los cielos y está en el santuario celestial $(9,11-27)$. Es precisamente por esto que el creyente puede tener la certeza de un acceso nuevo a Dios y conoce el camino de este accoso: Jesús $(10,19-23)$.

47. Teleios: 5,14; 9,11; teleiotés: 6.1 ; teleioo: 2,$10 ; 5,9 ; 7,19.28 ; 9,9 ; 10,1.14 ; 11,40$; 12,23; teleiosis: 7.11 (telos: $3,6.14 ; 6,8.11 ; 7.3$ ).

48. Sobre el tema de la teleiósis cf. A. Vanhoye, Prétres anciens prétre nouveau, pp. 152-156. Sin embargo, conviene notar tes cosas sobre este punto: a) el verbo te- 
leioun en la traducción griega de los LXX (con la que el autor de Hebreos era muy familiar) sirve para traducir el hebreo millé' yad, que se relaciona siempre con la consagración sacerdotal según la ley de Moisés (cl. Ex. 29) y tiene, por tanto, claras connotaciones para el autor de Hebreos; b) el medio de ser "perteccionado" es paradójicamente el sufrimiento (Heb. 5,7-10 cf. Fil. 2,5-11); c) la proclamación de la consagración de Jesús se hace por medio del oráculo divino (SI, 110,4), es decir, por la palabra de Dios que penetra radicalmente la realidad y la puede transformar por dentro (cf. Heb. 4, 12-13).

49. La afirmación es de A. Vanhoye, Situation du Christ, p. 71 ; Prêtres anciens, prêtre nouveau, p. 84. H. Braun se muestra reticente: An die Hebräer, p. 33.

50. Egéneto en 5,9 (cf. hina eleêmon genêtai, 2,17; ouch eauton edoxasen gênêthênai archierea, 5,5; archiereys genomenos eis ton aiôna, 6,20; hos... gegonen, 7,16; gegonen engyos lésous, 7,22). Puede verse lo que diœe en este sentido A. Vanhoye, Situation du Christ, p. 71. Sin embargo, conviene explicitar algo suficientemente importante sobre estos textos: todos están o bien en aoristo o en perfecto. Ya C. Spicq notaba la sorprendente frecuencia del perfecto en la carta (L'Epitre aux Hébreux, vol. I, cap. 12: "Langue et caracteristiques littéraires," pp. 351-378, más concretamente pp. 366-367). El uso cristológico del perfecto confiere a la terrenalidad de Jesús un cierto carácter de perpetuidad (ct. por ejemplo 7,14 (anatetalken); 2,14 (peponthen) y los participios élattömenon 2,9 y pepeirasmenon 4,15).

51. Que la confesión sea o no directamente cristológica no afecta a nuestro argumento. Cf. la nota 36 supra.

52. "De "aspectu" oblationis Christi secundum Epistolam ad Hebreos," publicado en Verbum Domini37 (1959) 32-39.

53. Los textos se encuentran en los siguientes fragmentos: a) 5,1-3 (prospherein) - 5,7 (prosenenkas.. emathen.. epathen); b) 7,27a (anapherein) - 7,27b (epoiêsen... anenenkas); c) 9,7 (prospherei) - 9.12 (eisêlthen... 9,14 prosênenken); d) 9,25 (prospherei) - 9,24 (eisélthen... 9.28 prosenechtheis); e) 10,1 (prospherousin) 10,12 (prosenenkas.. ekathisen).

54 Esto no lo nota Vanhoye en el trabajo citado. Sin embargo, todos los textos excepto 5,7 (que puede explicarse de otra forma) tienen o bien hapax (9.28), o bien ephapax $(7,27 \mathrm{~b} ; 9,1210,10)$ y finalmente mia thysia $(10,12)$.

55. "Aspectus" durativus de "perfectione" $(7,28)$, de vita et intercessione $(7,25)$, de sessione etiam Christi $(12,2)$ affirmatur, de sacrificio autem Christi, de oblatione, de ingressu in coelum, nunquam. Per sacrificium suum unicum, Christus intravisse in coelum dicitur; illud sacrificium in coelo perdurare in Hebr. certe non dicitur," A. Vanhoye, art.c. en la nota 53, p. 39.

56. Este es el acento del hapaxy del ephapax. Cf. lo que decimos en la nota 8 supra.

57. La vida de Jesús es descrita mediante categorlas sacerdotales como se hace patente a través de los aoristos citados en la nota 53. Sin embargo, hay que tener en cuenta que la transformación de Jesús en un nuevo tipo de sacerdote es debida a la acción de Dios. Por ello hay que tener presente que si por un lado se describe a Jesús como sacerdote en su vida mortal, en cambio la calidad sacerdotal de Jesús es un don de Dios (cf. supra, nota 48, letra c).

58. Un pasado que perdura en algunas de sus vertientes más profundas: cf. supra, nota 50 y mi trabajo "El cuarto evangelio y el tiempo," publicado en Estudios Eclesiásticos 57 (1982) 129-154.

59. Heb. $9,27-28$ y la nota 8 supra.

60. Véase el trabajo sobre el sentido de la presentación narrativa del evangelio de Juan que hemos citado en la nota 1.

61. Con esta comparación no pretendemos identificar la cristologla de estas dos obras.

Se trata simplemente de notar su innegable cercania. Cf. la nota 16 supra. 
62. ¿Un ángel? Asi parece que puede interpretarse: $M$. d'Angelo, Moses in the letter to the Hebrews, SBLDS 56, Chico C.A. 1983.

63. Véase la nota 25 supra.

64. Aparte del conocido texto de 12,2: "aphorontes eis ton... archêgon kai teleiôten lêsoun," otros textos que hablan de Jesús contienen una exhortación a contemplar, considerar, acercarse, salir hacia este Jesús (cf. blepomen 2,9; katanoêsate 3,1 ; proserchometha 4,16 ; hós ankyran... esierchomenên.. hopou prodromos hyper hémón eisêlthen lésous 6,19-20; proserchomenous 7,25; proserchometha 10,22; exerchometha 13,12). Todos estos textos confieren a Hebreos un talante contemplativo muy peculiar que debería ser analizado más de cerca.

65. Novedad especialmente clara y sorprendente respecto de la tradición neotestasmentaria conocida, ef. A. Vanhoye, Prêtres anciens, prêtre nouveau, pp. 87-91.

66. Dice M.M. Bourke a ralz de Heb. 2,17: "Esta es la primera vez que se menciona el tema central de Heb: la tunción de Jesús como sumo sacerdote. Al decir de él que es 'fiel,' el autor se sitúa en una tradición que exigía esta cualidad de todo sacerdote (cf. 1Sam. 2,35), pero el que haya de ser "compasivo" es una idea peculiar de $\mathrm{Hb}$," op.c. (en la nota 2$)$, p. 333.

67. "Cuando en 4,15 y en 5,1-3 se vuelve a tomar este motivo de la compasión del sumo sacerdote, estará basado, como aquí $(2,17)$, en su solidaridad con los hombres. Nada hay en el AT que subraye esta cualidad; probablemente deriva de la reflexión personal del autor acerca del tenor de la vida terrena de Jesús, de su sulrimiento y de su muerte," ibid. p. 333. Estas afirmaciones son muy parecidas a las de J. Roloff: Der hier $(5,1-3)$ vorliegende typologische Vergleich ist nicht apologetisch sondern christologisch conzipiert, art. c. en la nota 6, p. 149 cf. también pp. 150 y 152 y la nota 22 de la página 149.

68. No es necesario que el autor haya conocido la tradición sinóptica acerca de las tentaciones de Jesús para afirmar que éste no cayó en pecado. Por otra parte el participio de perfecto pepeirasmenon $(4,15)$ subraya que las tentaciones no se dieron una sola vez. Es toda la vida de Jesús la que es contemplada por Hebreos como vida de fidelidad. Sobre esto volvemos más adelante.

69. Heb. 12,2 cf. la nota 64 . supra.

70. Cf. la cita y el comentario del SI. 40,8-9 en Heb. 10,7.9.10. La interpretación de la eulabeia de Jesús en Heb. 5,7 no está muy lejos de este cumplir la voluntad de Dios. La TOB traduce eulabeia por soumission.

71. Estos datos ya los apuntaba C.H. Dodd en 1938 en su obra History and the Gospel, London, pp. 68-69. E. Grässer los ha completado: "Der historische Jesus..." (citado en la nota 6), pp. 69-70. No pretenden ser una lista completa, sobre todo después de lo que diremos más adelante.

72. El trabajo de E. Grässer (cf. supra nota 6) se centra precisamente en mostrar que los datos aparentemente "históricos" de Hebreos sobre la vida de Jesús no tienen finalidad biográfica de ningún tipo. Su trabajo concluye que el interés del autor de $\mathrm{He}$ breos por la crónica o la biografla es nulo, art. c., p. 91.

73. No todos de la misma manera. Más en concreto 7,$14 ; 5,7$ y 13,12. Esta es también la conclusión de Grässer, art. c., p. 91.

74. Como hemos indicado antes se trata de una presentación tradicional y podemos sospechar que, en el fondo, la homología de la comunidad está centrada en esta exposición cristológica que viene de la tradición. Hay que recordar, con todo, lo que hemos dicho en la nota 36.

75. Este es posiblemente el punto más flojo del magnífico trabajo de J. Roloff (citado supra en la nota 6). Según este autor el criterio decisivo de cara a valorar la realidad del Jesús terreno en Hebreos deberla ser el esquema de la historia salutis. Sin embar- 
go, hay otros libros neotestamentarios que, sin emplear este esquema, han dado una valoración muy profunda de la realidad terrena de Jesús. Puede verse lo que expuse en este sentido en el trabajo citado en la nota 1.

76. Creo que es verdad que esto resulta muy conocido. Pero el problema está en dejar que Hebreos hable no solamente con sus propios conceptos, sino también y sobre todo con su propio horizonte hermenéutico. Es decir, sin sobreimponerle un esquema que, sienda válido para otros escritos, sin embargo, puede resultar deformante del pensamiento de este escrito peculiar. Más en concreto, sin presuponer que Hebreos tiene el mismo concepto de historia que los escritos lucanos. Sobre esto volveremos en la conclusión.

77. Sobre la identidad entre el anthropos y el huios tou anthrôpou cf. E. Grässer, "Beobachtungen zum Menschensohn im Hebr 2,6," publicado en el Festschrift A. Vôgtle Jesus und der Menschensohn, Freiburg i. B. 1975, pp. 404-414.

78. El verbo griego usado aquf tiene resonancias innegables: se trata de tener en común, koinóneo.

79. H. Braun, An die Hebräer, p. 64.

80. En definitiva porque se trata de una cuestión demasiado seria para discutirla en un trabajo tan limitado como el presente. Hasta qué punto la antropología de Hebreos es susceptible de una interpretación gnóstica es algo que ha de quedar abierto. Sin embargo, todo nuestro trabajo parece más bien apuntar a una interpretación antropológica estrictamente blblica y, en este sentido, muy alejada de la gnosis.

81. $4,15 \mathrm{cf}$. la nota 68 supra.

82. Todos estos datos deberian ser ampliados y estudiados mucho más a fondo. Porque en defínitiva es toda la antropología de Hebreos que se debería analizar mucho más ya que lo que hemos indicado a ralz de estos datos es que hay, en Hebreos, una dialéctica entre cristologla y antropologla y que ambas se enriquecen mutuamente. La antropologla del autor (con una serie de datos sobre la vida del hombre, sobre el sufrimiento, la debilidad, el miedo a la muerte y la naturaleza misma de la muerte) se ha protundizado de la mano de la cristologla. Pero también la cristologla se ha apoyado en la antropologla. Estas mutuas implicaciones deberlan estudiarse más a fondo.

83. Esta interpretación probablemente no la suscribirian todos los exegetas de Hebreos, pero el talante de las exhortaciones que tenemos en 10,19-39 y en 12,1-13,21 apunta más bien a un enraizamiento en la realidad y la dureza de la vida cotidiana que a escaparse para vivir en el cielo.

84. Heb. 13, 16.

85. So wenig bleibt noch Raum fü ein kultisches Denken, dass die Venwendung kultischer Terminologie zum Mittel wird, paradox die Tiefe des Umbruchs zu verdeutlichen. Im eschatologischer Zeit ist nichts mehr profan, das nicht der Mensch profanisiert und dämonisiert, darum aber auch nichts mehr im kultischen Sinne heilig ausser der Gemeinde der Heiligen und ihrer Hingabe im Dienste des Herrn, dem die Welt in all ihren Bereichen gehört, E. Käsemann, "Gottesdienst im Alltag der Welt. Zur Römer 12", publicado originalmente en el Festschrift J. Jeremias y que ha sido reproducido en Exegetische Versuche und Besinnungen, vol. II. Göttingen ${ }^{1968}$. pp. 198-204, cita de la p. 201.

86. En este punto hay que situar la intuición de $O$. Cullmann de tratar el título de archiereys como aplicado a la existencia tertena de Jesús y que tiene indudablemente su validez después de lo que hemos dicho en estas páginas. Cf. su trabajo citado supra en la nota 6.

87. Esta es la contribución más interesante del trabajo de J. Roloff citado en la nota 6. Puede verse sobre todo lo que dice en las pp. 148-151.

88. Su interpretación y uso del AT parece haber escogido otro camino: el de la tipologla y los hypodeigmata. Véase también lo que decimos en la nota siguiente. 
89. El tema del concepto de tiempo en Hebreos rebasa los estrechos limites de este trabajo. Sin embargo, dada la cercania con otros documentos neotestamentasrios (por ejemplo el evangelio de Juan), hay que hacer alguna indicación sobre el mismo: a) el autor de Hebreos no considera el tiempo como una magnitud intocable; en este sentido pueden aducirse una serie de datos: los "dias" duran años $(4,7)$, el "hoy" cúltico se alarga indefinidamente $(3,7.13 .15)$ y alcanza a los contemporáneos del autor $(3,13)$, la figura de Melquisedec es asimilada a la de Jesús y coetánea con él $(7,3)$, la nube de testigos del AT se hace presente al lector $(12,1)$; b) Jesucristo es ayer, hoy y será el mismo para siempre $(13,8)$, es decir, a él pertenecen el pasado, el presente y el futuro (cf. 7.24 y 1,13); c) el abajamiento del hijo respecto de los ángeles se da brachy ti, un poco, $(2,7.9)$, con la ambigüedad de si este "poco" es una indicación espacial o temporal. En una palabra: tenemos en Hebreos una valoración muy ágil del tiempo cronométrico. Parece que el tiempo se encoge. No se niega la realidad del tiempo como duración (al fin y al cabo Jesús ha de volver, $9,28, y$ el último dla se acerca, 10,25). Tal vez esta relativización del tiempo entendido como magnitud cronométrica es lo que posibilita una presentación cristológica tan madura. Por lo menos deberíamos analizar este punto más de cerca y ver si presenta una cierta homogeneidad con la concepción que subyace al evangelio de Juan. Véase lo que decimos en este sentido en los trabajos citados en la nota 1 y en las notas 18 y 58 supra.

90. "Hacia una determinación de la realidad sacerdotal," publicado en Revista Latinoamericana de Teologia 1 (1984) 47-81, cita de la p. 68 (la presentación de Jesús sacerdote en Hebreos que se encuentra en las pp. 68-75 coincide en muchos puntos con la argumentación que hemos hecho en estas páginas).

91. Cf. A. Vanhoye, Le Message de l'Epître aux Hébreux, Cahiers d'évangile 19, Paris 1977, pp. 11-18.

92. Recordemos lo que sobre la confesión hemos dicho supra en la nota 36.

93. Cf. la nota 1 supra.

94. Esta afimación no es un locus communis de los escritos del Nuevo Testamento, sino que tiene una especificidad en Hebreos: kratómen tês homologias $(4,14)$ y katechómen tên homologian tês elpidos (10,23), cl. también 3,1 y 13,15.

95. Aunque no parece que el acento haye de recaer en el aspecto de peregrinación como postulaba E. Käsemann en su tesis, A. Vanhoye, "Longue marche ou accés tout proche? Le contexte biblique de Héb 3,7-4,11," publicado en Biblica 49 (1969) 926.

96. Véase lo que decimos en la conclusión del trabajo sobre Juan citado en la nota 1 , pp. 28-31. 